\title{
Influence of certainty of notions about identity on teenagers' radicalization
}

\author{
Kirill Zlokazov ${ }^{1}$, Marina Krivoshchekova ${ }^{2}$, and Maria Voroshilova ${ }^{3, *}$ \\ ${ }^{1}$ St. Petersburg University of the Ministry of Internal Affairs, Saint-Petersburg, Russia \\ ${ }^{2}$ Ural State Pedagogical University, Kosmonavtov Str., 26, 620017Ekaterinburg, Russia \\ ${ }^{3}$ Ural Institute of Management - Branch of RANEPA, 8 Marta Str., 70, 620144 Ekaterinburg, Russia
}

\begin{abstract}
The article discusses the problem of counteracting teenagers' radicalization. It's assumed that radical attitudes in teenagers' environment negatively effect the formation and development of society. It's underlined the growing desire to involve teenagers and youth in carrying out extremist and terrorist acts. Also there are considered modern theoretical concepts of radicalization, their specific essence. It's noted that all concepts take into account the role of disturbed or hampered social relationship as a latent factor of radicalization. On this basis we made the assumption about the influence of one's representations about oneself on radicalization.

A hypothesis is advanced about the influence of the certainty of identity on the manifestation of radical fanatical and nationalist convictions. Then the purpose, methods and procedure of empirical investigation of the certainty of self-identity and social identity are described, the sample of the study included 140 teenagers of 12 to 14 ages, $49 \%$ - male. It's estimated the influence of the variables a) the certainty of self-identity; b) the certainty of social identity on the variables c) the fanatical attitude and d) the nationalistic attitude. One-way ANOVA is used as the main method.

The results show that the uncertainty of self-identity reduces teenagers' fanatical beliefs, and the certainty of social identity raises them. The parameters of the identity have no effect on the nationalist beliefs..
\end{abstract}

\section{Introduction}

Radicalization is the process of forming beliefs about the appropriateness of using violence (Wilner et al., 2010). Prevention of teenagers' radicalization is a key task of a society that is interested in stability and development, as in future, teenagers' radicalization can evolve into youth's radicalization and further, to effect society on the whole.

The criminal statistics confirm our fears: at present the level of crimes and offenses committed for extremist reasons tends to increase (Khlebushkin, 2014). Accordingly, the latent component of such crimes is following - the level of radicalization is at a sufficiently high level; and as a result, modern teenagers are in the risk-zone of criminalization. Examples of organizations (ISIS, etc.), which activity is prohibited on the territory of the

\footnotetext{
* Corresponding author: shinkari@mail.ru
} 
Russian Federation, show that their participants are mainly young people of different nationalities (Dalton et al., 2014).

We conducted an evaluation of extremist ideologies, which are spread on the territory of the Russian Federation, to determine the types of radicalization. The study showed two main varieties: 1) fanatic follow-up to the canons of religion, conviction of the primacy of religious dogmas over secular norms; 2) radical nationalism, which develops the idea of the superiority of one nationality over another. Moreover, fanaticism and nationalism are accompanied by xenophobia - a fear of representatives of social groups that differ in religious, political features and authoritarianism - the conviction about the acceptability of a power but not a democratic solution of socio-political, religious and other problems of society. These ideas are propagated in various ways among Russian teenagers. Means of propaganda are not only books, videos or audio fragments, but also images, appeals, applied in the form of graffiti (Vorobyeva et al., 2016). Besides, extremist views are actively disseminated in the Internet.

It is important to emphasize that teenagers, by virtue of their ages, are the "target" audience of extremist communities. On the one hand, they haven't reached the age of criminal responsibility, on the other hand, they are social active and strive for independence. Another alarming indicator is the series of extremist acts, which were done by young people. It can be assumed that extremist ideologists return to the tactics of "leaderless" terrorism (Sageman, 2014), considering it as more appropriated for achieving their goals. Thus, in recent years, the traits of "a single wolf" are seen in terrorist's sociopsychological portrait - it is an unsociable young man or girl who is keen on the ideas of the struggle for justice (Spaaij, 2014).

Prevention of teenagers' radicalization is a complex task, based on a clear idea of the mechanism of its formation, inducing factors and signs that allow it to be diagnosed. Radicalization should be considered as a complex phenomenon, prompted by a multitude of efforts, an essentially unexplained action of the only one reason (Schmid, 2013). In the present work, its socio-psychological aspects are discussed and analyzed only, while the authors realize the importance of the influence of other components.

There are currently three explanations of radicalization in social psychology. The first, the concept of personal traits, connects radicalization with the properties of personality (Spaaij, 2010). The second focuses on the effect of ideological readiness on radicalization (Klausen et al, 2016). Third is the concept of a radical personal-social type; according to it, extremist behaviour is formed on the basis of subject's existing settings in special circumstances of the situation (Moskalenko et al., 2011).

Despite the differences, the presented concepts assess the role of the social environment in the formation of readiness for radical and extremist actions almost in a similar way. It is the nature of interaction with the social environment that reinforces the idea of violence as a way of solving social problems. The idea of violence arises in people's minds of different nationalities, political and religious, types of temperament, personality traits

Studying of the biographies of extremists and terrorists outlined that those who showed interest in radical and extremist ideas had problems with integration into society. For example, T. Precht notes that radicalization is based on a feeling of dissatisfaction with life, society, socio-economic situation (Precht, 2007).

Subject's negative relations with the group also effect on the radicalization of behaviour. They can be connected with the exclusion of the subject from the group, his non-involvement in the relations of the group members or other actions that lead to isolation. Following the views of S.Moskalenko, radicalization can be determined by an intergroup conflict, where the subject is a member of a group criticized by other groups (Moskalenko et al., 2011). A similar point of view is developed by S.D. Reicher, shows that 
members of a group can purposefully form a relation of hatred and enmity to other social groups (Reicher et al., 2008).

So, the formation of radical views of individuals and social groups occurs in the context of violations of social interaction. However, the measurement of them all requires a complex research and long-term interviews. In our opinion, the problems of social interaction can be explored and explained in a simpler form, by studying the subject's ideas about himself and his social presence. As our analysis shows, social interaction forms the subject's self-representations. As a result, the self-concept captures the actual state of relations between the subject and the social environment (Zlokazov, 2017). Violations of social interaction are also realized by the subject. Their signs are contradictory selfdetermination, dissatisfaction with self-embodiment, experience of peer rejection, denial of behaviour prescribed by social groups.

Accordingly, the study of teenagers' self-representations can be a useful indicator of monitoring radicalization. At the same time, the concepts of self-representations are diversed and require clarification about the influence of self-representations on social behaviour. Its brief results are presented in the next section of the article

\section{Problem statement}

The analysis is devoted to the disclosure of causes of teenagers' exposure to the radicalization. The authors focus on the causes caused by disturbances in the interaction of a teenager with the surrounding social world, realizing that this point of view is narrow, since it covers only the socio-psychological aspects, avoiding the evaluation of personality traits or the influence of a social group. The interest is prompted by an obvious circumstance - most concepts of radicalization designate the role of problems or failures of the subject's social interaction in the formation of radical motivation in one or another way, but not enough reveal them. In addition, in this context, there is a lack of scientific knowledge about the role of negative self-representations in the determination of radical behavior.

The authors refer to the socio-psychological concepts of identity to develop these assumptions, explaining how the subject's representation of himself and his position in social relations is formed and how it effects on social behavior.,

Theories of social identity show that identity is the result of cognitive efforts to build an image of oneself (Berzonsky, 2013). The role of identity is to evaluate the integrity of the subject's ideas about himself. Since the subject represents himself in two perspectives: himself as a whole, and himself in social relations, then identity has also two varieties.

The first, self-identity, describes the measure of the integrity and identity of a person's ideas about himself as an individual, detached and self-sufficient, taken outside the context of social relations. The second type, social identity, characterizes the subject's idea of himself in the context of social relations. It shows the identification of the subject with social roles, the regulation of his behaviour by social norms and rules. A similar view of identity is developed in the context of socio-cognitive theories (Berzonsky, 2011). Unlike the psychoanalytic approach of identity, the cognitive view of identity implies that it's realized and used by the subject. In particular, identity is used for self-assessment, decisionmaking and interaction.

But the idea of identity of the subject isn't stable and permanent (Luyckx et al., 2006). That is, having arisen once in a more or less successful form it doesn't remain stable for life. Instability of identity is caused by the fact that the subject is constantly looking for new ways of self-realization, in addition, he is under the influence of people and life circumstances (Waterman, 1982). Such image of identity was characterized by J.E. Marcia (Marcia, 1966). He considered that identity is formed in childhood, teens and adolescence, 
ranging from diffuse (blurred) identity to acquired (holistic, sustainable). Diffuse identity makes social interaction difficult, and acquired one, contributes to it.

A number of researchers suggest that a person has a need for a clear and definite identity, so he makes determined efforts to clarify and specify it (Brewer, 1991). Sometimes cardinal changes are made in one's own life to understand oneself: old relationships are broken up, the way of life changes, new ideas are accepted. Involvement in radical, protest extremist groups is also considered as one of the ways to build a clear and consistent identity (Hogg et al., 2013).

These assumptions haven't yet received sufficient empirical confirmation in the Russian-speaking sample of teenagers. We are conducting research, the hypothesis of which is the assumption of the influence of the uncertainty of notions of identity on the severity of radical representations and extremist settings.

Definition of identity expresses the subject's representation that he, his decisions or actions meet the requirements of the social world. The determination of identity is indicated by an understanding of the social causes of one's behaviour, knowledge of the rules, norms and requirements of a social group. Uncertainty of social identity means a person's lack of understanding of requirements, ignorance of the rules of interaction with members of a social group. In general, the certainty of identity indicates successful social integration, and uncertainty signals about problems in teenagers' interaction with society.

Thus, the idea of our research is, by assessing the certainty of identity, to determine its effect on teenagers' radical beliefs

\section{Empirycal Study}

The purpose of the study was to test the influence of the teenagers' identity on their support of fanatical, nationalistic, xenophobic and authoritarian ideas.

The empirical study was based on the assumption that the certainty of identity influenced on the level of acceptance (consensus) fanatical, nationalistic, xenophobic and authoritarian beliefs. In terms of the tools that we have used, we studied the effect of the certainty of a) self-identity and b) social identity, on the level of nationalist and fanatical beliefs.

The main method of the research was an interview. Standardized self-report and a questionnaire were used.

1. Self-Report: "Questionnaire of Personality Identification Processes" (Zlokazov, 2017) includes 33 statements, and each statement has four variants as answers. Each variant characterizes the manifestation of one property of identity: 1) definite productive; 2) definite unproductive; 3 ) indefinite productive; 4) undefined unproductive. 16 statements characterize self-identity, 16 - social identity. 1 approval is a service one, necessary for the training.

The study used two indicators: 1. "Self-Identity"; 2. "Social identity" for each of which was estimated the degree of certainty of the views of each testee.

2. Questionnaire of socio-psychological analysis of extremist-destructive attitudes of an individual. (Zlokazov, 2014). The questionnaire includes 11 items that involve replies using the «Likert's scale». They are grouped into 4 main scales: "Fanaticism", "Nationalism", "Xenophobia", "Authoritarianism". High values of indicators on the scales characterize the consent of the interrogated with ideas associated with fanatical, nationalistic, xenophobic and authoritarian views. The study used two indicators: "Fanaticism", revealed excessive adherence to religious beliefs and "Nationalism", showed the subject's preference of his nationality and hostility towards representatives of other nationalities.

Processing methods and interpretation. The questionnaire and self-report data were processed by means of computer software: Microsoft Exel, Statistica 10.0. The 
interpretation was carried out by calculating measures of the central tendency, a singlefactor dispersion analysis (one way anova). Due to the limited sample size, the combined effect of identity indicators on the level of indicators of fanatical, nationalistic, xenophobic and authoritarian settings was not studied, and the effect of the sex factor on susceptibility to radical settings was not studied also.

Organization of the study. The research was carried out in Ekaterinburg. The sample of the study was collected in schools. 140 people were interviewed in the course of the study, at the age between $12-15(\mathrm{M}=13.2$ years, $\mathrm{SD}=3.13), 49 \%$ of respondents - male.

\section{Findings}

The statistical regularities of the influence of definiteness and the productivity of identity on the teenagers' adoption of fanatical, nationalistic, xenophobic and authoritarian beliefs were found out.

1. Uncertain self-identity increases teenagers' acceptance of fanatical ideas (F-crit. (1. 139) $=5.21, \mathrm{p}=.001)$.

2.Certain social identity increases susceptibility to fanatical ideas (F-crit. (1. 139) $=4.26, \mathrm{p}=.02$ ).

None of the types of identity had a statistically significant effect on the level of the nationalistic setting.

\section{Conclusion}

The research was aimed at finding out socio-psychological reasons of teenagers' radicalization. The work considered violations of social interaction as a reason. Using the concept of identity, we assumed that the problems of interaction were fixed by the subject in the notion of one's own identity. It's assumed that the vague idea of identity influenced on teenagers' radicalization, as the desire for a clear self-representation encouraged them to more radical strategies of social behaviour.

The results obtained in the empirical study confirmed the hypothesis, pointing the role of identity in radicalization according to a fanatical (religious) type. Particular, it was established that the certainty of identity affected the fanatical attitude of the subject in teens. The certainty of self-identity reduced fanatical beliefs, and the certainty of social identity - strengthened them.

Psychological meaning is seen in the peculiarities of teenagers' attitude to religion and religious behaviour. On the one hand, clear teenagers' representations about themselves reduce the influence of religious beliefs on behaviour. On the contrary, an intricate, vague idea of self and diffuse self-understanding leads to a preference of religious norms for social. We emphasize that these conclusions were obtained with reference to the average and low levels of the "fanatical" indicator, i.e. don't imply a serious effect of religious ideas on self-attitude and behaviour.

At the same time, the fact under discussion emphasizes the role of religion in teenagers' self-representations. One should agree with an empirical analysis of beliefs and religion (Samykina et al., 2014), which shows that the essence of religion is not fully realized in teens. Therefore, in the self-awareness of teenagers religious beliefs are contrasted with secular ones, as a result, social models of behaviour exclude religious ones.

The obtained results indicate a symbolic splitting: clear teenagers' self-representation excludes religiosity, and confusing - includes. The problem is that trying to define one's own identity through religion can have catastrophic consequences. The tactics of spreading the ideology of Islamic fundamentalism, distributed in the Internet, illustrates our concerns. 
Its propaganda is built on the ideas of gaining clarity and self-knowledge, all sorts of blessings and happiness by following a radical pattern of behaviour - destruction of unbelievers. So, a teenager gets under the destructive propagandists' influence trying to self-determine and build his identity.

This is evidenced by another, more understandable result of our study - a certain social identity enhances the level of fanatical settings. Due to the peculiarities of age, teenagers are especially sensitive to the opinion of peers and adults who establish "trust" relationships with them. Considering himself as a member of an extremist group, even virtual, the teenager values this idea sincerely, strives to meet the requirements of "new friends".

Through the prism of the discussed results, the psychological and pedagogical prevention of radicalization must be built in obvious directions: firstly, through the construction of a clear and specific model of self-representation in teens; secondly, through the formation the ideas about the socialized practices of religiosity in teenagers, suggesting the development of a consistent understanding of the role of religion in life.

An unexpected result was that identity didn't influence on the nationalist setting. Psychological explanation of this is seen in the peculiarities of propaganda of nationalism. Now, the predominant ways of representing it are images and video fragments that arouse feelings of anxiety and fear. As a rule, they make the image of the "enemy" of the nation, attributing to it cruelty and strength, and at the same time affirming the weakness of Russian society and the incapacity of Russian law enforcement agencies. But such nationalistic and xenophobic effects don't lead to any result.

We'll sum up: the study revealed the influence of teenagers' notions of identity on the formation of fanatical radical beliefs. Thus, the theoretical assumption about the effect of identity on social behaviour and interaction was confirmed. We have concluded that the construction of self-identity among Russian teenagers has cultural-specific features: teenagers are susceptible to religious norms and religious behaviour because of the uncertainty of self-representations.

The main methodological result was the understanding of the possibility of predicting teenagers' radicalization by studying the certainty of self and social identity. From a psycho-correctional point of view, the results can be used in reducing the level of radicalization through changing teenagers' perceptions of self-identity. And, finally, the results showed the importance of social control over social groups that popularize practices of self-development and self-improvement in the teenagers' environment

\section{Acknowledgment}

This study was prepared under financial support of Russian Science Foundation (RSF) grant, project 17-18-01278

\section{References}

1. M. D. Berzonsky, Handbook of Identity Theory and Research (2011)

2. M. D. Berzonsky, Identity, 3(2) (2003)

3. M. B. Brewer, Personality and Social Psychology Bulletin, 17(5) (1991)

4. M. Dalton, M. Coker. The Wall Street Journal (2014)

5. M. A. Hogg, A. Kruglanski, K. van den Bos, Journal of Social Issues, 69(3) (2013).

6. A.G. Khlebushkin, Society and law, 4 (2014) 
7. J. Klausen, S. Campion, N. Needle, G. Nguyen, R. Libretti, Studies in Conflict \& Terrorism, 39(1) (2015

8. K. Luyckx, L. Goossens, B. Soenens, W. Beyers, Journal of Adolescence, 29(3) (2006)

9. J. E. Marcia, Journal of Personality and Social Psychology, 3(5) (1966)

10. S. Moskalenko, C. McCauley, Counselling Psychology Quarterly, 24(2) (2011)

11. T. Precht, Danish Ministry of Justice (2007)

12. S. Reicher, S. A. Haslam, R. Rath, Social and Personality Psychology Compass, 2(3) (2008)

13. M. Sageman, Understanding Terrorist Networks (2004)

14. N. U. Samykina, E. U. Stroganova, The idea of faith and religion in adolescents and students, Samara: Center for the Development of Education (2014)

15. A. Schmid, P. Radicalization, De-Radicalization, Counter-Radicalization: A Conceptual Discussion and Literature Review: International Centre for CounterTerrorism - The Hague Research Paper (2013)

16. R. Spaaij, Studies in Conflict \& Terrorism, 33(9) (2010)

17. R. Spaaij, M. S. Hamm, Studies in Conflict \& Terrorism, 38(3) (2014)

18. I. V. Vorobyeva, O. V. Kruzhkova, N. E. Zhdanova, Russian psychological journal, 13 (2016)

19. A. S. Waterman, Developmental Psychology, 18(3) (1982)

20. A. S. Wilner, C.-J. Dubouloz, Global Change, Peace \& Security, 22(1)

21. K. V. Zlokazov, Bulletin of the St. Petersburg University of the Ministry of Internal Affairs of Russia, 1 (2014) 